\title{
Exame de Citologia Oncótica: a perspectiva das mulheres em duas unidades básicas de saúde do sudeste da Amazônia legal brasileira
}

\author{
Cytology examination: the expectation of women in two primary health care units in \\ southeast of the brazilian legal Amazon
}

\section{Examen de citología oncótica: la expectativa de las mujeres endos unidades de atención primaria de salud en el sudeste de la Amazonía legal brasileña}

Raynara Thatielle Barbosa Fernandes ${ }^{1 *}$, Denise Soares de Alcântara ${ }^{1}$, Fabiola Bento Araújo1, Andreia Kássia Lemos de Brito ${ }^{1}$, Gisela Daleva Costa ${ }^{2}$ Sandra Nara Marroni ${ }^{1}$, Marcia Andréa Marroni', Leandra Cristhyne de Souza Barros ${ }^{1}$, Claúdia Christina Ribeiro Guimarães Neri de Magalhães ${ }^{1}$, Lourrayne Michelle Dantas de Oliveira Bartolomeu'1.

\section{RESUMO}

Objetivo: Conhecer a perspectiva das mulheres adescritas em Unidades Básicas de um município do Estado do Tocantins sobre o exame de citologia oncótica. Métodos: Trata-se de um estudo exploratório descritivo realizado por meio de entrevista guiada por um instrumento semiestruturado nos meses de agosto a outubro de 2019. Os resultados foram analisados pela técnica de análise de conteúdo. O estudo foi aprovado por Comitê de Ética em Pesquisa. Resultados: A maior parte das entrevistadas afirmaram esperar por bons resultados do exame, apresentaram conhecimento distorcido da finalidade da citologia oncótica e relataram sentir vergonha, medo e constrangimento durante a coleta. Conclusão: As mulheres apresentaram como principal perspectiva que o resultado do exame citológico não apresentasse alterações que comprometessem sua saúde, além de descreverem sentimentos negativos que podem justificar a baixa procura pela realização.

Palavras-chave: Neoplasias do colo do útero, Teste de papanicolaou, Acesso aos serviços de saúde.

\begin{abstract}
Objective: To know the perspective of women enrolled in Basic Units of a municipality in the State of Tocantins in the examination of oncotic cytology., about the oncotic cytology exam. Methods: This is an exploratory descriptive study conducted through an interview guided by a semi-structured instrument from August to October 2019. The results were analyzed using the content analysis technique. The study was approved by the Research Ethics Committee. Results: Most interviewees said they expected good results from the exam, had distorted knowledge of the purpose of oncotic cytology and reported feeling shame, fear and embarrassment during collection. Conclusion: The main perspective presented by women was that the result of the cytological examination did not present any alterations that could compromise their health, in addition to describing negative feelings that may justify the low demand for the performance.
\end{abstract}

Keywords: Cervical neoplasms, Papanicolaou test, Health services accessibility.

\section{RESUMEN}

Objetivo: conocer la perspectiva de las mujeres matriculadas en unidades básicas de un municipio del estado de Tocantins en el examen de citología oncótica. Métodos: Este es un estudio exploratorio descriptivo realizado a través de una entrevista guiada por un instrumento semiestructurado de agosto a octubre de 2019. Los resultados se analizaron utilizando la técnica de análisis de contenido. El estudio fue aprobado por el Comité de Ética en Investigación. Resultados: La mayoría de los entrevistados dijeron que esperaban buenos

${ }_{1}^{1}$ Universidade de Gurupi, Gurupi-Tocantins. *E-mail: raynarathatiellenferma@gmail.com 
resultados del examen, habían distorsionado el conocimiento del propósito de la citología oncótica y reportaron sentir vergüenza, miedo y vergüenza durante la recolección. Conclusión: La perspectiva principal de las mujeres era que el resultado del examen citológico no presentaba alteraciones que pudieran comprometer su salud, además de describir sentimientos negativos que pueden justificar la baja demanda de rendimiento.

Palabras clave: Neoplasias cervicales, Prueba de papanicolaou, Acessibilidad a los servicios de salud.

\section{INTRODUÇÃO}

O câncer de colo uterino (CCU) é um problema de saúde pública tanto em países desenvolvidos como em desenvolvimento. No Brasil é o terceiro câncer maligno mais frequente na população feminina, ficando atrás somente do câncer de mama e do colorretal, além de representar a quarta causa de morte de mulheres por câncer, sendo a falta de acesso aos serviços de saúde descrita como um dos agravantes para seu desenvolvimento (INCA, 2019).

Em 2018, as estimativas do Instituto Nacional do Câncer (INCA) eram de 16.370 casos novos da doença, om ameaça de 17 a 11 casos a cada 100 mil mulheres. No Sistema de Informação sobre Mortalidade (SIM), $\mathrm{m} 2017$, foram registradas 6.385 mortes, números que mostram a triste realidade da doença no Brasil (INCA, 2019).

Vários fatores de risco estão relacionados ao desenvolvimento do CCU, como começo precoce da atividade sexual, múltiplos parceiros, infecções sexualmente transmissíveis recorrentes, tabagismo, uso prolongado de pílulas anticoncepcionais, nível socioeconômico baixo e multiparidade (INCA, 2019).

As infecções persistentes pelo vírus do Papilomavírus (HPV) do tipo HPV 16 e HPV 18 são as principais causas no desenvolvimento do Câncer de colo uterino. O HPV é transmitido principalmente pelo contato sexual sem proteção e, quando a doença neoplásica se desenvolve, a mulher tem como sintomas: sangramento vaginal anormal, dor pélvica, fadiga, desconforto vaginal, leucorréia com odor fétido, dentre outros mais graves, se a doença tiver estágios mais avançados (CARVALHO FOIC, et al., 2019).

Diversas ações podem ser realizadas para prevenção do CCU, entretanto o exame de citologia tem sido apontado como o melhor método de detecção precoce das células cancerígenas. Este também pode receber outras denominações como: colpocitologia oncótica, citologia vaginal, citologia oncótica e papanicolau (ADDE C, 1999; SILVEIRA BL, et al., 2018).

O exame citológico é um exame de baixo custo e eficaz realizado nas consultas de planejamento familiar, pré-natal, consultas ginecológicas de rotina e de livre demanda em muitas Unidades Básicas de Saúde (UBS) do país com o intuito de diminuir a incidência de CCU ou diagnosticar precocemente a patologia (JORGE RJB, et al., 2011; ROCHA BD, et al., 2012).

Embora o exame de citologia seja considerado o melhor método para detecção precoce do câncer do colo uterino e esteja disponível gratuitamente na rede pública de saúde, muitas mulheres não o realizam por diversos motivos, que variam desde sentimentos negativos como vergonha, medo, desconforto, desconfiança, nervosismo e insegurança, até dificuldades de acesso ao serviço como desinformação, falta de tempo, rotina de trabalho, não ter onde deixar os filhos e o desencorajamento pelo parceiro (AMORIM VMSL, et al., 2006; FERREIRA MLSM, 2009; CHICONELA FV e CHIDASSICUA JB, 2017; ONOFRE MF, et al., 2019).

A perspectiva das mulheres quanto à realização do exame de citologia é influenciada por seus valores, cultura, etnia e, principalmente, pelas experiências vividas durante a coleta do material.

Deste modo, os profissionais de saúde, principalmente os enfermeiros - por serem os responsáveis diretos pela realização do exame na maioria dos serviços, devem acolher a mulher considerando sua história de vida, crenças, tabus, fantasias, cognição e cultura. (CUNHA ES, 2015; GARCIA CL, et al., 2010).

Neste contexto, o presente estudo teve como objetivo conhecer a perspectiva das mulheres adscritas nas Unidade Básicas de Saúde (UBS) de um município do Estado do Tocantins sobre o exame de Papanicolau. 


\section{MÉTODOS}

Trata-se de um estudo exploratório descritivo, realizado nas UBS, situadas na zona urbana de um município do Estado do Tocantins. Estas unidades foram escolhidas por serem campo de estágio das pesquisadoras e por terem sido apontadas pela Secretaria de Saúde como UBS's com alta demanda de mulheres. Os dados foram coletados nos meses de agosto a outubro de 2019 nos dias de atendimento à saúde da mulher.

Participaram da pesquisa 10 mulheres com idade de 25 a 55 anos, que realizaram o exame de citologia nas respectivas UBS e que aceitaram participar da pesquisa - após esclarecimento e assinatura do Termo de Consentimento Livre e Esclarecido. O número de entrevistadas por UBS foi delimitado pelo critério de saturação.

Foram excluídas mulheres menores de 18 anos, histerectomizadas e portadoras de distúrbios mentais. Os dados foram coletados por meio de entrevistas individuais, guiadas por um instrumento semiestruturado elaborado pelas pesquisadoras, contendo perguntas claras e objetivas relacionadas a expectativa das mulheres acerca do exame de citologia.

As entrevistas foram gravadas em aparelho MP4 e transcritas na íntegra para posterior categorização. Para análise dos resultados utilizou-se a técnica de análise de conteúdo proposta por Bardin (2011). Da análise emergiram 5 categorias: expectativa das mulheres sobre o exame de citologia, sentimento das mulheres quanto a realização da citologia, orientações recebidas sobre o exame papanicolau, importância e frequência do exame citológico, percepção da mulher quanto ao profissional que conduz o exame.

Para preservar a identidade das entrevistadas, seus nomes foram representados por um sentimento de sua escolha, os quais foram tratados de 1 e 2 quando a escolhida se repetiu pelas entrevistadas nos dois locais da pesquisa. Este estudo foi aprovado pelo Comitê de Ética e Pesquisa da Universidade Unirg sob o parecer № 3.503.246. Conforme normas da Resolução 466/2012 do Conselho Nacional de Saúde.

\section{RESULTADOS E DISCUSSÃO}

De acordo com o Ministério da Saúde brasileiro (MS), a detecção precoce de lesões percussoras do câncer de colo do útero, através do exame de citologia oncótica, é uma das estratégias de prevenção secundária mais eficazes, refletindo em redução da mortalidade por esta patologia. Entretanto, para o sucesso desta estratégia, é necessário que as mulheres realizem periodicamente o exame preventivo. Mas, as mulheres esbarram em diversas barreiras que interferem na assiduidade da realização do exame (MS, 2013; SILVA MAS, et al., 2015).

Nesse contexto, esta pesquisa busca responder a seguinte questão norteadora "Qual a perspectiva das mulheres sobre a realização do exame Papanicolau?", onde os resultados foram demonstrados em cinco categorias: "Perspectivas das Mulheres sobre o exame de citologia oncótica", "Sentimento das mulheres quanto a realização do exame de citologia", "Orientações recebidas sobre o exame de citologia", "Importância e frequência do exame citológico" e "Percepção da mulher quanto ao profissional que conduz o exame".

Quanto aos aspectos sociodemográficos, foram entrevistas dez mulheres, das quais sete apresentavam idades entre 25 e 35 anos, e três com idade entre 45 e 55 anos. Se tratando do nível de escolaridade $20 \%$ possuíam ensino fundamental incompleto, 30\% ensino fundamental completo, 40\% ensino médio e 10\% ensino superior. No que diz respeito ao estado civil, $40 \%$ eram casadas, $30 \%$ solteiras e $30 \%$ em união estável. No que se refere a ocupação $60 \%$ eram empregadas domésticas, $20 \%$ do lar, 10\% agente comunitária de saúde e $10 \%$ professora.

\section{Perspectiva das mulheres sobre o exame de citologia oncótica}

Brito CMS, et al. (2007) relatam que mesmo a mulher realizando a citologia oncótica periodicamente, a relação profissional-paciente não é o suficiente para que os profissionais reconheçam os diferentes sentimentos envolvidos durante a coleta do exame. Ainda há uma preocupação da classe feminina com o resultado da citologia, em que referiram um maior medo com o diagnóstico de câncer. 
As entrevistadas relataram como expectativas quanto ao exame: agilidade na realização, prevenção de doenças, busca pelo diagnóstico, tratamento de sintomas e resultados negativos para enfermidades, como transcrito abaixo:

"Minha expectativa é essa de fazer logo e terminar logo\{...\}" (Entrevistada 1).

"Esperança né que livra toda doença\{...\}" (Entrevistada 2).

"É porque toda muié tem que fazer né porque é bom pra gente fazer porque preveni muitas coisas né\{...\}" (Entrevistada 3).

"Ue porque eu to e usando pra fazer pra terminar uma secreçãozinhaque ta tendo a e melhorar ter melhora\{...\}" (Entrevistada 4).

"É cuidar da saúde né?! \{...\}" (Entrevistada 5).

"É uma expectativa assim de saber resultados bons que venha bons resultados\{...\}" (Entrevistada 6).

"E que eu não tenha nada, que não de nada e que dê tudo certo\{...\}" (Entrevistada 7).

"Bom minha expectativa é que não de nada né no exame\{...\}" (Entrevistada 8).

"A expectativa de que a cada exame que a gente faizi a gente encontra uma solução de descobrir algo realmente no útero da gente\{...\}” (Entrevistada 9).

Observou-se que as mulheres que buscam o exame de citologia sentem a expectativa de que seu resultado seja bom, que não tenha nada de errado, nada de ruim. Sendo que a possibilidade de um resultado negativo causa ansiedade e apreensão, muitas mulheres realizam o exame e não retornam mais na unidade para saber o resultado, o medo do resultado afasta a mulher do cuidado com a sua saúde. Isto torna imprescindível que a mulher seja bem esclarecida sobre as possibilidades de tratamento e cura da doença, caso o resultado seja negativo, bem como da necessidade da frequência da prevenção do câncer uterino; realizando o exame na periodicidade recomendada pelo Ministério da Saúde.

\section{Sentimento das mulheres quanto a realização do exame de citologia}

As mulheres deste estudo vivenciaram sentimentos negativos na realização do Papanicolau, como desconforto, vergonha, constrangimento e medo. A vergonha torna-se um impedimento enorme para execução do exame e pode causar até interrupção da assistência.

A exposição do corpo no decorrer do procedimento de coleta citopatológico é algo intenso para mulher, pois a coloca em situação de fragilidade, na qual é exposta ao toque e manipulação do seu corpo por outra pessoa (CARVALHO FOIC, et al. 2018).

"Um desconfortozinho, um pouco de vergonha\{...\}" (Entrevistada 3).

"Eu vou mentir não, sinto vergonha, muita vergonha, faço mermo porque eu gosto de cuidar da minha saúde sempre gostei, mas sinto vergonha, muita não sei se é porque eu sou vergonhosa\{...\}" (Entrevistada 5).

"Ah!Eu sinto um desconforto\{...\}" (Entrevistada 6).

"Dependendo do profissional que eu vou encontrar eu fico tranquila só na hora, mas antes eu fico bem tensa\{...\}" (Entrevistada 1).

Os serviços e profissionais de saúde que realizam o papanicolau devem estar preparados para satisfazer as necessidades das mulheres, entendendo que cada mulher é única, devendo atendê-la de maneira individualizada e holística.

A enfermagem envolvida neste contexto deve ser capaz de proporcionar as mulheres a capacidade de se empoderar, de cuidar do próprio corpo desmistificando os sentimentos negativos que a realização da citologia pode causar. 
"Às vezes constrangimento\{...\}" (Entrevistada 8).

"Vergonha\{...\}" (Entrevistada 2).

"O medo de na hora que eles colocar e sentir alguma dor e isso ai que eu sinto\{...\}" (Entrevistada 7).

"Medo, vergonha, medo, de apresentar alguma coisa\{...\}" (Entrevistada 4).

A vergonha e o medo tornam o exame preventivo algo constrangedor, desconfortável e que apesar de ser importante na percepção da maioria das mulheres, os sentimentos negativos fazem com que deixem de realizar a coleta. Em alguns casos as mulheres sentem-se inferiorizadas, demonstrando medo e vergonha de se expor, principalmente para um médico (FERREIRA MLSM, 2009). Precisa ser esclarecedora, acolhedora e que inspire confiança e segurança à mulher para que ela se sinta menos constrangida na hora do exame.

\section{Orientações recebidas sobre o exame de citologia}

A maior parte das entrevistadas disseram ter sido orientadas sobre o exame de citologia, no entanto as falas revelam que muitas não compreenderam a finalidade do exame.

"já, me deram muitas informação e né negocio de inflamação de câncer um bucado muitas informação eu já recebi\{...\}" (Entrevistada 2).

"Já, porque a gente tem que fazer né porque previne muitas doenças veia né e bom fazer mermo eu quero fazer hoje porque eu to sentindo uma dorzinha veia no pé da barriga tambem e eu fui um dia consultar o dotor disse igual eu já passei da idade de fazer num pricisava eu ta fazendo mas ai eu vou fazer porque eu to sentindo essas dorzinha \{...\}" (Entrevistada 3).

"Já questão que pra que é o exame, que o exame ajuda a prevenir o câncer de color do útero ajudar a mulher se cuidar ne questão menstrual né \{...\}" (Entrevistada 5).

"Já, que é um exame que a gente faz pra descobrir algo que tiver dentro prejudicando a gente $\{. . .$.$\} ” (Entrevistada 6).$

"Já, informação que a gente fazendo ele você vai diagnosticar pra saber se seu útero ta limpo se tem alguma doença pra você já começar fazer o tratamento \{...\}" (Entrevistada 4).

"Eu já assistir uma palestra aqui mesmo nesse postinho, como seria feito porque deveria ser feito o que iria prevenir que iria mostrar\{...\} (Entrevistada 7).

"Já, ah eu nem lembro informações assim o que é como é feito que as vezes dói $\{\ldots\}$ (Entrevistada 8).

"Sim, a única informação que ela me deu é o que exame é muito bom pra mim descobrir se realmente a gente tem o câncer do colo do útero e uma que vai muito além ainda também pode descobrir outras doenças\{...\}" (Entrevistada 8).

Ações educativas proporcionam maior sensibilização e conscientização sobre a importância do autocuidado, favorecendo a adesão, a realização do exame preventivo do câncer do colo uterino, principalmente, na devida frequência.

"Não nunca fui orientada não\{...\}" (Entrevistada 1).

"Não, orientações e pra tomar remédio essas coisas assim\{...\}" (Entrevistada 3).

Os profissionais de saúde precisam estar mais próximos da comunidade, conhecendo suas necessidades, sanando dúvidas e proporcionando informações relevantes para promoção e prevenção da saúde. $O$ programa de estratégia da saúde da família é uma ferramenta que facilita este encontro; percebemos neste estudo, diante da desinformação de algumas mulheres, que existe uma lacuna a ser preenchida principalmente pelos enfermeiros, que tem a educação em saúde inerente a sua profissão. 


\section{Importância e frequência do exame citológico}

As mulheres relataram a importância da realização do exame e a frequência em que elas realizam. No que diz respeito à importância, todas consideraram o exame importante para a prevenção de doenças, conforme descrito abaixo:

"A é muito importante creio que sim que é muito importante sim serve pra evitar doenças $\{. .$.$\} " (Entrevistada 1).$

"Acho\{...\}" (Entrevistada 2).

"Eu acho muito importante\{...\}" (Entrevistada 3).

"Sim\{...\}" (Entrevistada 4).

"Eu acho importante porque é coisas que a mulher não faz direto né mulher demora muito pra fazer não todas algumas\{...\}" (Entrevistada 6).

"Com certeza\{...\}" (Entrevistada 7).

"Sim\{...\}" (Entrevistada 8).

Brito CMS, et al., (2007) dizem que as mulheres dão importância à citologia oncótica para descobrir alguma patologia, em especial, o câncer de colo de útero - por ser uma doença que causa medo - e ainda também para ser usada como forma de se prevenir.

O fato de reconhecerem a importância do exame facilita a adesão a esta prática, tornando-as conscientes de sua responsabilidade no cuidado de sua saúde. A maioria das mulheres desta pesquisa apontaram ser importante fazer o exame preventivo, tanto que realizam periodicamente como constatado abaixo.

"A é uma vez no ano\{...\}" (Entrevistada 1).

"Eu faço todo ano tem que vez que eu faço duas vezes no ano eu já fiz duas vezes no ano\{...\}" (Entrevistada 2).

"Eu fazia de seis e seis meses $\{. .$.$\} " (Entrevistada 3)$

"Quando não faço de seis e seis meses eu faço de ano e ano\{...\}" (Entrevistada 5).

"Todo ano\{...\}" (Entrevistada 7).

"De ano e ano\{...\}" (Entrevistada 8).

"De seis em seis meses\{...\}" (Entrevistada 8).

O reconhecimento da importância da realização do exame preventivo pode ser evidenciado com a frequência em que é feito.

O Ministério da Saúde recomenda que toda mulher com idade entre 25 e 64 anos que tem ou já tiveram vida sexual realize o exame de Papanicolau, devendo os dois primeiros ser anuais e caso sejam negativos devem ser repetidos a cada três anos (INCA, 2019).

Observou-se que algumas mulheres não foram totalmente sensibilizadas quanto a frequência ideal para coleta do exame. Como transcrito abaixo;

"Demorou muitos anos pra mim fazer sete anos\{...\}" (Entrevistada 6).

"Ta com uns três anos que não faço\{...\}" (Entrevistada 4).

Proporcionar informações corretas e adequadas é papel dos profissionais de saúde, manter a comunidade alerta sobre as maneiras de promoção, proteção e prevenção á sua saúde são ações garantidas por lei a população e os profissionais que atuam no SUS tem esta obrigação.

Os enfermeiros neste contexto podem colaborar no rastreamento das mulheres que nunca realizaram 0 exame de citologia oncótica, bem como, com as mulheres que não realizam dentro da frequência preconizada, fazendo busca ativa e convocação quando necessário. 


\section{Percepção da mulher quanto ao profissional que conduz o exame}

Nesta categoria buscou descrever o que as mulheres acham do profissional que realiza a coleta do exame. Como transcrito abaixo:

"Bom eu acho um profissional mesmo não me sinto envergonhada quando eu vou realizar o exame conversa me deixa bem à vontade\{...\}" (Entrevistada 1).

"Aqui eu achei maravilhoso\{...\}" (Entrevistada 2).

"Profissional é bom né porque já ajuda até a gente porque ta fazendo o exame na gente\{...\}" (Entrevistada 3).

"Bom simpático acolhedor\{...\}" (Entrevistada 4).

"Bom quando eu fiz foi boa foi bem conversou me deixou tranquila relaxou então foi muito bom\{....\}" (Entrevistada 5).

"Muito bom\{...\}" (Entrevistada 6).

"Muito bom até agora todos que vinheram pra mim foram muito boas são responsáveis\{...\} (Entrevistada 8).

O profissional de enfermagem tem um papel de suma importância quando o assunto é prevenção em saúde. $O$ fato de o enfermeiro estar em contato direto com as mulheres que buscam atendimento nas unidades básicas cria-se um vínculo de confiança. $O$ atendimento apoiado neste vínculo é a melhor forma de reforçar o compromisso entre profissionais e mulheres atendidas e o diálogo é de total importância em todos os momentos do atendimento à mulher (OLIVEIRA SL, ALMEIDA ACH, 2009).

\section{CONCLUSÃO}

O presente estudo mostrou que a maior expectativa das mulheres em relação ao exame de citologia é principalmente pelo resultado, elas esperam que estes não apresentem alterações importantes, apesar de não saberem o principal objetivo da realização deste exame. Os sentimentos negativos vivenciados pelas mulheres podem ser fatores que contribuam para que deixem de fazer o exame, observou-se que 0 constrangimento, por se colocar em nudez, é um grande problema durante a realização do exame de citologia. O relacionamento profissional-paciente deve ser fortalecido de modo a proporcionar empatia, segurança e confiança às usuárias. Medidas simples que podem diminuir os índices de CCU por aumentar a demanda de procura e realização do exame de citologia.

\section{AGRADECIMENTOS}

Os autores agradecem à Secretaria Municipal de Saúde por autorizar a realização da pesquisa nas UBS's, bem como aos profissionais que nelas laboram e a todas as mulheres que aceitaram a participar da pesquisa.

\section{REFERÊNCIAS}

1. ADDE C. Prevenção diagnóstico e tratamento do câncer de colo do útero. São Paulo: Frôntis Editorial; 1999.

2. AMORIN VMSL, et al. Fatores associados à não realização do exame de Papanicolau: um estudo de base populacional no Município de Campinas, São Paulo, Brasil. Cad. Saúde Pública, 2006; v. 22, n. 11.

3. BARDIN L. Análise de Conteúdo. São Paulo: Edições 70, 2011.

4. MINISTÉRIO DA SAÚDE, Secretaria de Atenção à Saúde, Departamento de Atenção Básica. Controle dos cânceres do colo do útero e da mama, $2^{2}$ ed. Brasília (DF): Ministério da Saúde; 2013.

5. BRITO CMS, et al. Sentimentos e expectativas das mulheres acerca da Citologia Oncótica. Revista Pesquisa Brasileira de Enfermagem - REBEn, 2007; 60(4): 387-90.

6. CARVALHO FOIC, et al. Motivos que influenciam a não realização do Exame de Papanicolau segundo a Percepção de Mulheres. Rev Inic Cient e Ext. 2018; 1(5): 416-24.

7. CARVALHO KF, et al. A relação entre HPV e Câncer de Colo de Útero: um panorama a partir da produção bibliográfica da área. Revista Saúde em Foco, 2019; (11):268-270. 
8. CHICONELA FV, CHIDASSICUA JB. Conhecimentos e atitudes das mulheres em relação ao exame preventivo do câncer do colo uterino. Rev. Eletr. Enf, 2017; 19: 1-9.

9. CUNHA ES. Assistência de enfermagem na prevenção do câncer de colo uterino. FACIDER Revista Científica; 2015, (9): 1-4, 2015.

10. FERREIRA MLSM. Motivos que influenciam a não-realização do exame de Papanicolaou. Esc Anna Nery. Rev Enferm, 2009; 13 (2): 378-384.

11. GARCIA CL, et al. Percepção das mulheres acerca do exame de prevenção do câncer cervico-uterino. RBPS, 2010; 23 (2): 117-125.

12. GURGEL LC, et al. Percepção de mulheres sobre o exame de prevenção de colo de útero Papanicolau: Uma Revisão Integrativa da Literatura. Rev. Mult. Psic., 2019; 13 (46): 434-445.

13. INCA. INSTITUTO NACIONAL DO CANCÊR. Câncer de cólo do útero. Disponível em <https://www.inca.gov.br/tiposde-cancer/cancer-do-colo-do-utero>. Acesso em: 10 nov. 2019.

14. JORGE RJB, et al. Exame Papanicolau: sentimentos relatados por profissionais de enfermagem ao se submeterem a esse exame. Ciênc. Saúde Coletiva, 2011; 16 (5): 2443-2451.

15. OLIVEIRA SL, ALMEIDA ACH. A Percepção das Mulheres Frente ao Exame de Papanicolau: da Observação ao entendimento. Cogitare Enferm. 2009; 14(3): 518-526.

16. ONOFRE MF, et al. Principais fatores que dificultam a adesão ao exame de citologia oncótica: uma revisão de literatura. Enfermagem Revista, 2019; 22 (2): 231-239.

17. ROCHA BD, et. al. Exame de Papanicolau: Conhecimento de Usuárias de Uma Unidade Básica De Saúde. Rev Enferm UFSM, 2012; 2: 620-621.

18. SILVA MSA, et al. Fatores relacionados a não adesão à realização do exame de Papanicolau. Rev Rene, 2015 16(4): 532-539.

19. SILVEIRA BL, at al. Câncer Do Colo Do Útero: Papel Do Enfermeiro Na Estratégia E Saúde Da Família. Revista Científica da Faculdade de Educação e Meio Ambiente. Ariquemes: FAEMA, 2018; 9 (1): 349-350. 